\title{
RESEARCH
}

Open Access

\section{Effects of different plasma expanders on rats subjected to severe acute normovolemic hemodilution}

\author{
Guo-Xing You ${ }^{\dagger}$, Bing-Ting Li ${ }^{\dagger}$, Zhen Wang ${ }^{\dagger}$, Quan Wang, Ying Wang, Jing-Xiang Zhao, Lian Zhao ${ }^{*}$ and Hong Zhou*
}

\begin{abstract}
Background: Plasma expanders are widely used for acute normovolemic hemodilution (ANH). However, existing studies have not focused on large-volume infusion with colloidal plasma expanders, and there is a lack of studies that compare the effects of different plasma expanders.

Methods: The viscosity, hydrodynamic radius $\left(R_{h}\right)$ and colloid osmotic pressure (COP) of plasma expanders were determined by a cone-plate viscometer, Zetasizer and cut-off membrane, respectively. Sixty male rats were randomized into five groups with Gelofusine (Gel), Hydroxyethyl Starch 200/0.5 (HES200), Hydroxyethyl Starch 130/ 0.4 (HES130), Hydroxyethyl Starch 40 (HES40), and Dextran40 (Dex40), with 12 rats used in each group to build the ANH model. ANH was performed by the withdrawal of blood and simultaneous infusion of plasma expanders. Acidbase, lactate, blood gas and physiological parameters were detected.

Results: Gel had a lower intrinsic viscosity than HES200 and HES130 $(P<0.01)$, but at a low shear rate in a mixture of colloids, red cells and plasma, Gel had a higher viscosity $(P<0.05$ or $P<0.01$, respectively). For hydroxyethyl starch plasma expanders, the COP at a certain concentration decreases from $11.1 \mathrm{mmHg}$ to $6.1 \mathrm{mmHg}$ with the increase of $R_{h}$ from $10.7 \mathrm{~nm}$ to $20.2 \mathrm{~nm}$. A severe $\mathrm{ANH}$ model, with the hematocrit of $40 \%$ of the baseline level, was established and accompanied by disturbances in acid-base, lactate and blood gas parameters. At the end of ANH and 60 min afterward, the Dex40 group showed a worse outcome in maintaining the acid-base balance and systemic oxygenation compared to the other groups. The systolic blood pressure (SBP), diastolic blood pressure (DBP), and mean arterial pressure (MAP) decreased significantly in all groups at the end of ANH. The DBP and MAP in the Dex40 group further decreased 60 min after the end of ANH. During the process of ANH, the Dex40 group showed a drop and recovery in SBP, DBP and MAP. The DBP and MAP in the HES200 group were significantly higher than those in the other groups at some time points $(P<0.05$ or $P<0.01)$.
\end{abstract}

Conclusion: Gel had a low intrinsic viscosity but may increase the whole blood viscosity at low shear rates. $R_{h}$ and COP showed a strong correlation among hydroxyethyl starch plasma expanders. Dex40 showed a worse outcome in maintaining the acid-base balance and systemic oxygenation compared to the other plasma expanders. During the process of ANH, Dex40 displayed a V-shaped recovery pattern for blood pressure, and HES200 had the advantage in sustaining the DBP and MAP at some time points.

Keywords: Acute normovolemic hemodilution, Plasma expander, Acid-base, Lactate, Blood gas, Physiological parameters

\footnotetext{
* Correspondence: zhaolian@bmi.ac.cn; zhouhtt1966@163.com

${ }^{\dagger}$ Guo-Xing You, Bing-Ting Li and Zhen Wang contributed equally to this work.

Institute of Health Service and Transfusion Medicine, Bejing 100850, China
}

(c) The Author(s). 2020 Open Access This article is licensed under a Creative Commons Attribution 4.0 International License, which permits use, sharing, adaptation, distribution and reproduction in any medium or format, as long as you give appropriate credit to the original author(s) and the source, provide a link to the Creative Commons licence, and indicate if changes were made. The images or other third party material in this article are included in the article's Creative Commons licence, unless indicated otherwise in a credit line to the material. If material is not included in the article's Creative Commons licence and your intended use is not permitted by statutory regulation or exceeds the permitted use, you will need to obtain permission directly from the copyright holder. To view a copy of this licence, visit http://creativecommons.org/licenses/by/4.0/ The Creative Commons Public Domain Dedication waiver (http://creativecommons.org/publicdomain/zero/1.0/) applies to the data made available in this article, unless otherwise stated in a credit line to the data. 


\section{Background}

Acute normovolemic hemodilution $(\mathrm{ANH})$ is performed ahead of a procedure with a high risk of blood loss [1]. During ANH, whole blood from the patient is removed and replaced with a mixture of crystalloids and colloids to maintain the blood volume [1, 2]. ANH is widely applied for patients coming through cardiac surgery, particularly for those who refuse transfusion for religious or other reasons [3]. Moreover, ANH shows great prospects in patients coming through major hepatic surgery and other procedures associated with moderate-to-high blood loss (at least $1000 \mathrm{ml}$ ) [4]. ANH is also an effective and safe way to reduce the need for perioperative transfusion in pediatric patients receiving high bloodloss surgeries [5]. A meta-analysis has demonstrated that patients undergoing $\mathrm{ANH}$ have a clinically related reduction in red blood cell transfusions and a decreased incidence of transfusions with allogeneic blood [6]. ANH is regarded as an important clinical strategy for decreasing the use of allogeneic blood [7] and has been approved as a standard method of intraoperative blood conservation by the American Society of Anesthesiologists [3, 7].

The crystalloids and colloids used in ANH include balanced salt solutions, albumin solutions, and artificial plasma expanders. Plasma expanders are used commonly in mainland China and include succinylated gelatin injection (Gelofusine, Gel), Dextran 40 sodium chloride injection (Dex40), 200/0.5 hydroxyethyl starch and sodium chloride injection (Hydroxyethyl Starch 200/0.5, HES200), 130/0.4 hydroxyethyl starch and sodium chloride injection (Hydroxyethyl Starch 130/0.4, HES130) and hydroxyethyl starch 40 sodium chloride injection (Hydroxyethyl Starch 40, HES40).

Hydroxyethyl starch (HES) solutions, which is also commonly applied in shock treatments to increase the plasma volume [8], is a colloid solution classified by the molecular weight and the degree of substitution [9]. Gelatins are semisynthetic colloids obtained from the breakdown of collagen [9]. The use of HES130 in patients undergoing acute hemodilution reportedly results in better microvascular reactivity compared to the use of Gel [10]. Dextrans are polysaccharides that are available in multiple molecular weights [9], among which Dextran 70, Dextran 40 and Dextran 20 are widely used clinically. Animal studies have concluded that dextrans are effective plasma expanders that can decrease edema formation compared with crystalloids [11].

In recent years, the safety of using the above mentioned colloids intraoperatively has been extensively debated [12]. Large randomized controlled trials [13] have reported that the use of HES130 is associated with an increased risk of renal dysfunction in patients requiring renal replacement therapy and a higher mortality rate in patients with severe sepsis who receive 6\% HES130 [14].
The US Food and Drug Administration (FDA) has recommended that HES should not be applied in critically ill patients [9].

Despite these concerns, plasma expanders are still appropriate in certain situations. One study [15] reported that a patient, whose blood type was B and Rh-negative, successfully underwent extreme hemodilution with HES130, and another study [8] reported that HES is effective in improving acidosis in patients with aluminum phosphide poisoning. Furthermore, the Coordination Group for Mutual Recognition and Decentralized Procedures-Human, which is a medicinal regulatory body representing the European Union Member States, decided that HES should be used for infusion in clinical practice, provided that additional measures are implemented to protect patients [16].

Plasma expanders are still widely used for ANH currently. However, existing clinical studies have not focused on large-volume infusion with plasma expanders, and there is a lack of studies that compare the effects of different plasma expanders. Therefore, in the present study, a rodent model of severe ANH was established to compare the effects of different plasma expanders on the blood gas, acid-base balance and physiological parameters. The present findings may provide an experimental basis for large-volume infusion with plasma expanders in clinical practice and will provide an academic reference for the treatment of patients with severe trauma and massive bleeding.

\section{Methods \\ Measurement of physicochemical properties with plasma expanders \\ Blood samples were collected from Wistar rats. The} cone-plate viscometer (BT-300, Bright, China) was used to determine the intrinsic viscosity of the plasma expanders at a shear rate of $200 \mathrm{~s}^{-1}$. Whole blood was centrifuged at $3000 \mathrm{r} / \mathrm{min}$ and $4{ }^{\circ} \mathrm{C}$ for $10 \mathrm{~min}$, and then the plasma was separated and kept in a centrifuge tube. Red cell concentrates $(0.48 \mathrm{ml})$ were mixed with plasma $(0.42 \mathrm{ml})$ to get red cell suspensions. Plasma or plasma expanders $(0.3 \mathrm{ml})$ were added to the red cell suspensions to get the corresponding mixtures. The mixtures were incubated in a water bath (YHJD-05-1 L, Shanghai Pingxuan Scientific Instrument Co., Ltd., China) at $37^{\circ} \mathrm{C}$ for $15 \mathrm{~min}$, and afterward, the viscosity of the mixtures was determined at shear rates of 200,100,30, and $1 \mathrm{~s}^{-1}$ using a cone-plate viscometer.

The plasma expanders were diluted with phosphate buffer solution (PBS) to obtain a concentration of $0.05 \%$, and the hydrodynamic radius $\left(\mathrm{R}_{\mathrm{h}}\right)$ [17] of each plasma expander was determined by a Zetasizer (Nano2S, Malvern, China) at $25^{\circ} \mathrm{C}$. Plasma expanders in the intrinsic concentration of the injection were diluted with PBS to achieve a concentration of $2 \%$. A colloid osmometer (Osmomat 050, 
Gonotec, Germany) was used to measure the osmotic pressure of the colloids in the intrinsic concentration and diluted concentration (2\%).

\section{Animals}

All experiments were approved by the Laboratory Animal Centre of the Academy of Military Medical Sciences. Since researchers have found that there are gender differences in the morbidity and mortality from trauma and hemorrhagic shock (HS) [18, 19], in order to avoid gender effects and get homogeneous data, 60 male Wistar rats (270-340 g) purchased from Vital River Laboratories (Beijing, China) were randomly divided into five groups in the present study. Each rat was anesthetized via intraperitoneal injection with sodium pentobarbital (Peking Chemical Agent Co., China) $(50 \mathrm{mg} / \mathrm{kg})$. The rats were then put in the supine position on a heating pad (TMS-202, Softron, China) with a temperature of $37^{\circ} \mathrm{C}$.

\section{Experimental animal grouping}

The animals were randomly divided into 5 groups (12 rats for each group), as follows: 1) Gel group, 4\% Succinylated Gel (Gelofusine ${ }^{\oplus}$ B. Braun, Shenyang, China); 2) HES200 group, 6\% HES 200/0.5 (HAES-steril ${ }^{\circ}$, Fresenius-Kabi, Bad Homburg, Germany); 3) HES130 group, 6\% HES 130/0.4 (Voluven ${ }^{\bullet}$ Fresenius-Kabi, Bad Homburg, Germany); 4) HES40 group, 6\% HES40 (Shandong Qidu Pharmaceutical Co. China); and 5) Dex40 group, 6\% Dextran 40 (Shandong
Qidu Pharmaceutical Co. China). Each injection contained $\mathrm{NaCl}$ solution $(0.9 \%)$.

\section{Rodent model of ANH}

Both femoral arteries and the right femoral vein were isolated and cannulated with polyethylene catheters (PE50). The catheter inserted into the left femoral artery was used for blood withdrawal at the speed of $20 \mathrm{ml} / \mathrm{h}$ $[20,21]$, the catheter inserted in the right femoral vein was used for fluid infusion at the same speed, and the catheter in the right femoral artery was connected to a multiple-channel recorder (MP150, Biopac System, USA) for monitoring the blood pressure and heart rate (HR). The left jugular vein was isolated and cannulated to approximately $3.5 \mathrm{~cm}$ deep with a catheter for the measurement of the central venous blood gas.

The hemodilution approach is shown in Fig. 1, and it was performed in three steps. The first step of hemodilution (H1) was stopped when the Hct was reduced to $80 \%$ of baseline level, and this took approximately 20 min. In the following steps, the hematocrit (Hct) was reduced to $60 \%(\mathrm{H} 2)$ and $40 \%(\mathrm{H} 3)$ of the baseline level, taking approximately $30 \mathrm{~min}$ and $45 \mathrm{~min}$, respectively. $\mathrm{H} 3$ was the end of $\mathrm{ANH}$. After $\mathrm{H} 3$, the rats were monitored for $60 \mathrm{~min}$. The assessment time points were the baseline $(\mathrm{BL})$, the end of the first step of hemodilution $(\mathrm{H} 1)$, the end of the second step of hemodilution (H2), the end of the final step of hemodilution (H3), $10 \mathrm{~min}$ after H3 (10 min), $20 \mathrm{~min}$ after H3 (20 min), 30 min after

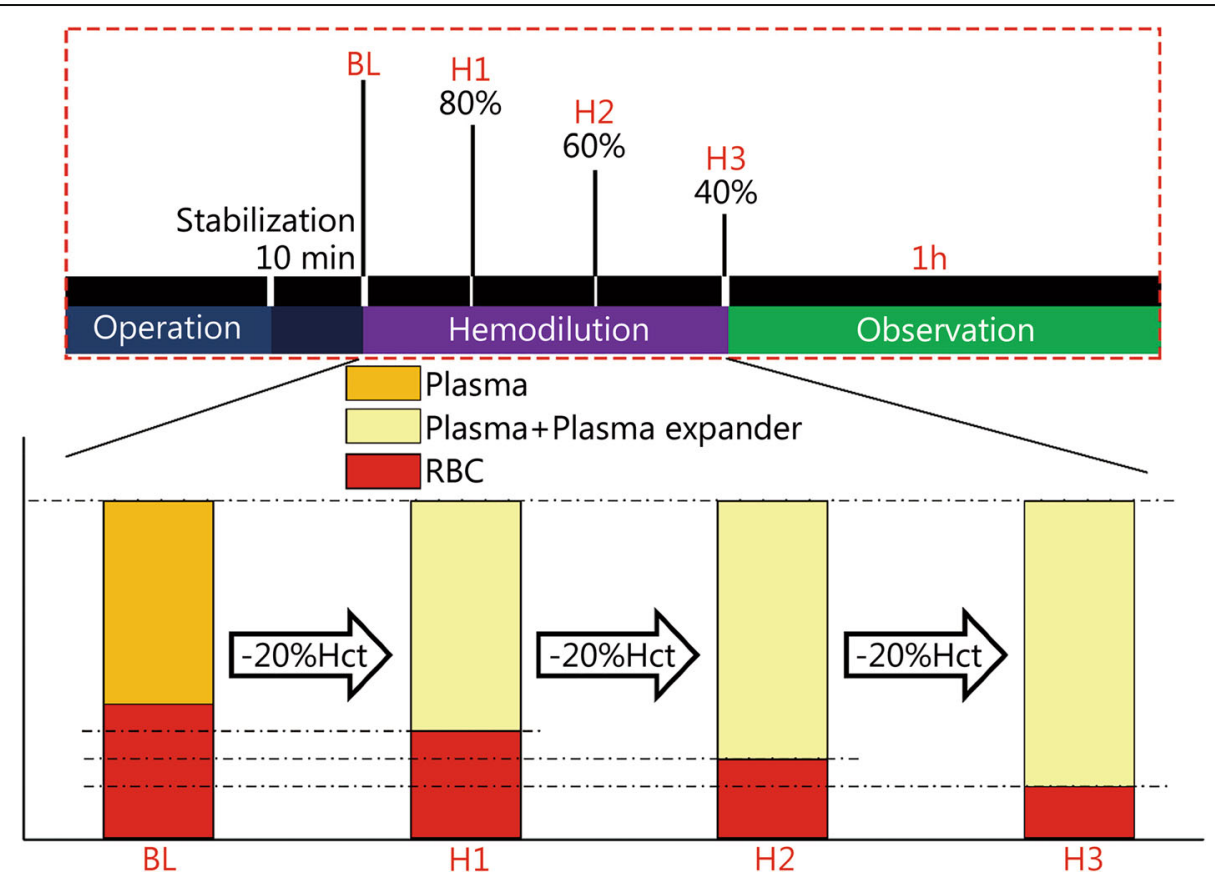

Fig. 1 Preparation of $\mathrm{ANH}$. ANH. Acute normovolemic hemodilution; BL. Baseline; H1. The end of the first step of hemodilution; H2. The end of the second step of hemodilution; H3. The end of the final step of hemodilution; RBC. Red blood cell; Hct. Hematocrit 
H3 (30 min) and $60 \mathrm{~min}$ after H3 (60 min). At the end of the experiment, according to the regulations for the administration of affairs concerning experimental animals, the animals were killed by cervical dislocation under anesthesia.

\section{Measurement of blood parameters}

The Hct and hemoglobin $(\mathrm{Hb})$ concentrations were measured by a semiautomated blood cell analyzer (Hemavet 950, Drew Scientific Inc., USA). The blood gas was determined by a blood gas analyzer (ABL80 FLEX, Radiometer Copenhagen, Denmark).

\section{Statistical analysis}

All data were examined for normality and homogeneity of variance. Comparisons among all groups at a single time point or among all time points within one group were performed using one-way independent ANOVA followed by Fisher's (LSD) post hoc analysis when the normal distribution or homogeneity of variance assumption was satisfied, and otherwise, the nonparametric Kruskal-Wallis test was used. The correlations between physiological parameters and blood gas parameters were analyzed by multiple linear regression, and the independent variables were screened by a step-by-step method. The correlation between the COP and $R_{h}$ of colloids was analyzed by two individual regression analysis. SAS 9.2 software (SAS Institute Inc., Cary, USA) was used to analyze the data, which are expressed as the mean \pm standard deviation $(\mathrm{M} \pm \mathrm{SD}) . P<0.05$ was considered to indicate a statistically significant difference.

\section{Results}

\section{Physicochemical properties of plasma expanders}

Figure 2a shows the intrinsic viscosity of the colloids. Gel had a lower intrinsic viscosity than Dex40, HES200, and HES130 $(P<0.01)$. Dex40 had a higher intrinsic viscosity than that of HES40 $(P<0.01)$. The viscosities of HES200, HES130 and HES40 decreased with the decrease of the molecular weight. The viscosities of the different colloids mixed with red cells and plasma at various shear rates are demonstrated in Fig. 2b. At a shear rate of $1 \mathrm{~s}^{-1}$, the mixture containing Gel had a higher viscosity than the mixtures containing plasma, HES200 and HES130 $(P<0.05$ or $P<0.01)$. The mixtures containing HES40 and Dex40 had higher viscosities than the mixtures containing plasma and HES200 $(P<0.05$ or $P<0.01)$. The mixture containing HES130 had a higher viscosity than the mixture containing plasma $(P<0.05)$. The mixtures containing Gel and Dex40 had higher viscosities than the mixture containing plasma at $30 \mathrm{~s}^{-1}$, $100 \mathrm{~s}^{-1}$, and $210 \mathrm{~s}^{-1}(P<0.01)$. Furthermore, Fig. 2c demonstrates the $R_{h}$ values of the different plasma expanders. The $R_{h}$ of HES200 was larger than the others $(P<0.01)$. HES130 had a larger $\mathrm{R}_{\mathrm{h}}$ than HES40 $(P<0.01)$, Dex40 and Gel $(P<0.05)$.

Figure $2 \mathrm{~d}$ shows the colloid osmotic pressure (COP) of plasma expanders at the intrinsic concentration of the injection, which was $4 \%$ for Gel and $6 \%$ for the others. The COP of HES200 was significantly lower than those of the other colloids $(P<0.01)$. The COP of Dex40 was significantly higher than those of the other colloids $(P<$ 0.01). The COP of Dex40 and Gel were significantly higher than that of HES130 $(P<0.01)$. To measure the $\mathrm{COP}$ at the same concentration, the colloids were diluted with PBS to achieve a concentration of $2 \%$, which is shown in Fig. 2e. HES200 had the lowest COP. HES40 had a higher COP than HES130 $(P<0.01)$. Dex40 had a higher COP than HES130 and HES40 $(P<0.01)$. The Gel had the highest COP.

The correlation between $R_{h}$ and COP of all colloids is demonstrated in Fig. 2f, and the coefficient of determination $\left(R^{2}\right)$ was 0.43 , which was statistically significant $(P<0.01)$. Furthermore, the correlations between the $R_{h}$ and COP of HES200, HES130 and HES40, which are all hydroxyethyl starches, are shown in Fig. 2g. The coefficient of determination $\left(R^{2}\right)$ was 0.97 , which was statistically significant $(P<0.01)$.

\section{Preparation of ANH model}

The hemoglobin $(\mathrm{Hb})$ concentration and Hct are demonstrated in Fig. 3. There were no significant differences between groups at any time point (Fig. $3 \mathrm{a}, \mathrm{c}$ ). $\mathrm{Hb}$ and Hct were lower at $\mathrm{H} 3$ and $60 \mathrm{~min}$ than at $\mathrm{BL}(P<0.01$, Fig. $3 b$ ), and they become higher at $60 \mathrm{~min}$ than at $\mathrm{H} 3$ (Fig. 3d).

\section{Acid-base and lactate parameters}

The acid-base balance was examined by measuring the $\mathrm{pH}$, base excess (BE), bicarbonate ion concentration $\left(\mathrm{HCO}_{3}{ }^{-}\right)$[22], and blood lactate concentration (Lac) to assess the tissue hypoxia of rats together with the blood gas parameters. The $\mathrm{pH}$ in the HES200 group was increased significantly at 60 min compared with $\mathrm{BL}$ and H3 $(P<0.01$, Fig. 4a). In the Dex40 group, the $\mathrm{pH}$ decreased gradually at $\mathrm{H} 3$ and 60 min compared with BL $(P<0.05)$. The $\mathrm{pH}$ at $\mathrm{H} 3$ and $60 \mathrm{~min}$ was lower in the Dex40 group than in the other groups $(P<0.05$ or $P<0.01)$.

In all groups, the actual $\mathrm{BE}$ levels and the $\mathrm{HCO}_{3}{ }^{-}$ levels of all groups decreased gradually from BL to 60 min after ANH $(P<0.01$, Fig. $4 \mathrm{~b}, \mathrm{c})$. At $\mathrm{H} 3$ and $60 \mathrm{~min}$, the $\mathrm{BE}$ and $\mathrm{HCO}_{3}{ }^{-}$levels were lower in the Dex40 group than in the other groups $(P<0.01)$. The Lac of all groups increased gradually from $\mathrm{BL}$ to $60 \mathrm{~min}(P<0.01$, Fig. $4 \mathrm{~d})$. The Lac was higher in the Dex40 group than in the other groups at $\mathrm{H} 3$ and $60 \mathrm{~min}(P<0.01)$. 


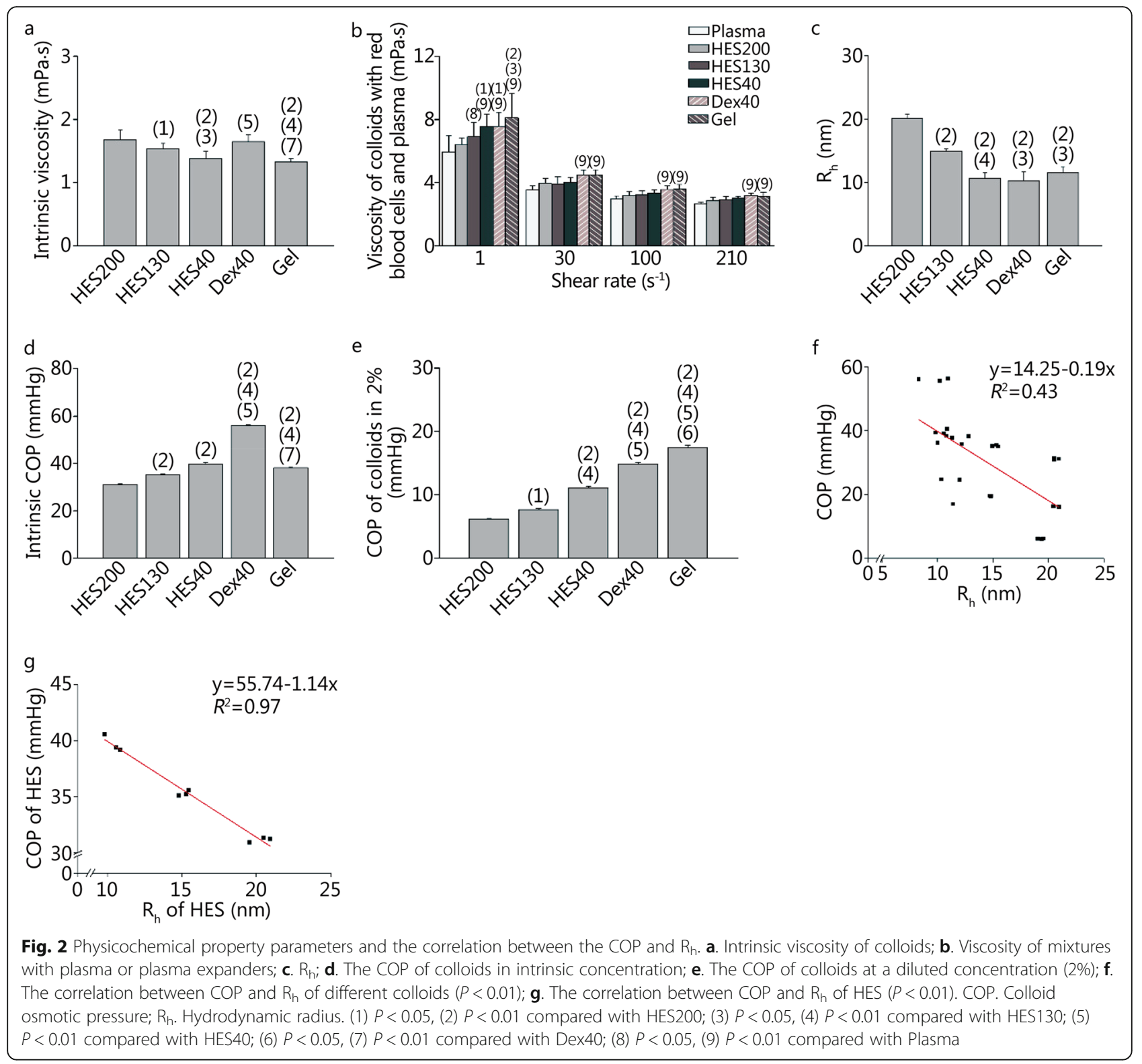

\section{Blood gas parameters}

To assess the tissue hypoxia of rats, the oxygen saturation in the central venous blood $\left(\mathrm{ScvO}_{2}\right)$, central venous oxygen partial pressure $\left(\mathrm{PcvO}_{2}\right)$, partial pressure of oxygen $\left(\mathrm{PaO}_{2}\right)$ and partial pressure of carbon dioxide $\left(\mathrm{PaCO}_{2}\right)$ were measured [23] and are demonstrated in Fig. 5. The $\mathrm{ScvO}_{2}$ (Fig. 5a), $\mathrm{PcvO}_{2}$ (Fig. 5b) and $\mathrm{PaCO}_{2}$ (Fig. 5d) of all groups decreased gradually $(P<0.01)$ and the $\mathrm{PaO}_{2}$ (Fig. 5c) increased gradually $(P<0.05$ or $P<0.01$ ) from $\mathrm{BL}$ to $60 \mathrm{~min}$ after $\mathrm{ANH}$. The $\mathrm{ScvO}_{2}$ was lower in the Dex40 group than in the Gel, HES200 and HES40 groups at $60 \mathrm{~min}(P<0.05)$. The $\mathrm{PaCO}_{2}$ was higher in the HES200 group than in the HES40 and Dex40 groups at $60 \mathrm{~min}(P<0.05)$.

\section{Physiological parameters}

To assess the cardiac function, tissue infusion, and microcirculation [24], the systolic blood pressure (SBP), diastolic blood pressure (DBP), mean arterial pressure (MAP), pulse pressure (PP) and heart rate (HR) were monitored. The SBP, DBP and MAP levels were significantly decreased $(P<0.01)$ at $\mathrm{H} 3$ compared with $\mathrm{BL}$ in all groups. The SBP increased significantly at $60 \mathrm{~min}$ in the HES200 and HES40 groups $(P<0.05)$, and the DBP and MAP decreased significantly $(P<0.01)$ at $60 \mathrm{~min}$ in the Dex40 group compared with those at H3 (Table 1).

The SBP, DBP and MAP levels decreased during the ANH. The SBP levels soon recovered towards the normal level during the observation phase, while the DBP 

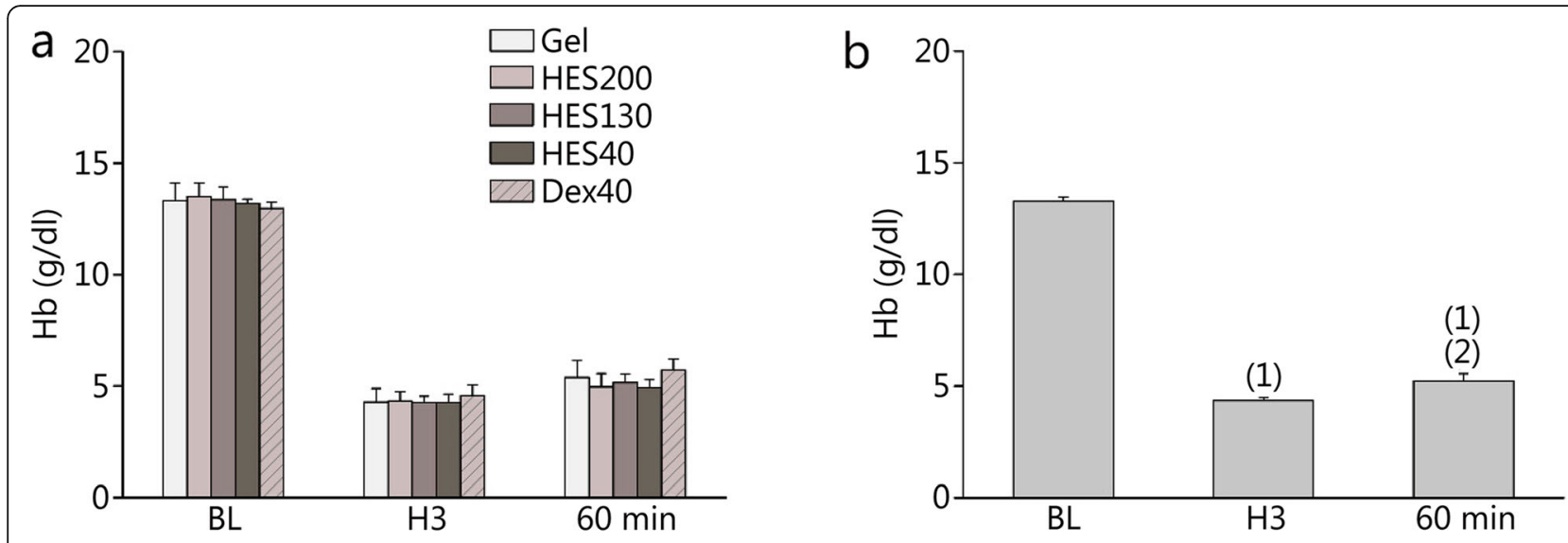

C

d
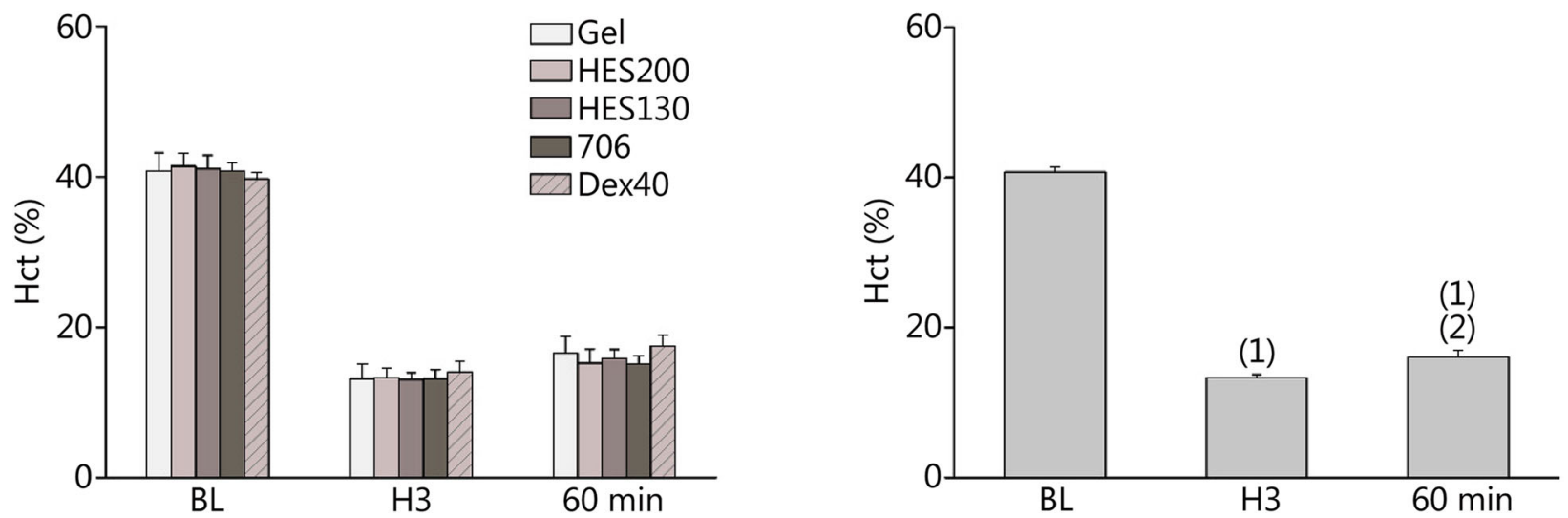

Fig. 3 Hematocrit (Hct) and hemoglobin (Hb) of rats that underwent $\mathrm{ANH}$. a, b. $\mathrm{Hb}$ at $\mathrm{BL}, \mathrm{H} 3$ and 60 min; $\mathbf{c}$, d. $\mathrm{Hct}$ at $\mathrm{BL}, \mathrm{H3}$ and 60 min. (1) $P<$ 0.01 compared with $\mathrm{BL} ;(2) P<0.01$ compared with $\mathrm{H} 3$

and MAP maintained decreased levels during the observation phase. The SBP, DBP and MAP levels decreased rapidly and suddenly in the Dex40 group at $\mathrm{H} 1$, with values lower than those in the other groups $(P<0.01)$. Then, it soon recovered at $\mathrm{H} 2$ but was significantly lower than in the HES200 and HES130 groups $(P<0.05$ or $P<0.01)$. The SBP level in the Dex40 group was significantly lower than those in the Gel, HES130, HES40 and HES200 groups at $60 \mathrm{~min}$ $(P<0.05$ or $P<0.01)$. The DBP level in the Dex40 group was significantly lower than that in the HES200 group at $\mathrm{H} 2$ and $20 \mathrm{~min}(P<0.05$ or $P<0.01)$, and it was significantly lower than those in the Gel, HES200 and HES130 groups $(P<0.05)$ at $30 \mathrm{~min}$, after which it was significantly lower than those in the HES200 and HES130 groups $(P<0.01)$ at $60 \mathrm{~min}$. The MAP level in the Dex40 group was significantly lower than that in the HES200 group at $\mathrm{H} 2$ and those in the other groups at $30 \mathrm{~min}(P<0.05$ or $P<0.01)$, and then it was significantly lower than those in the other groups $(P<0.01)$, except the HES40 group at $60 \mathrm{~min}$.
In addition to the significant differences of the SBP, DBP and MAP between the HES200 group and Dex40 group among time points, the SBP level in the HES200 group was significantly higher than those in the HES40 and Gel groups $(P<0.01)$ at $\mathrm{H} 2$, and it was also significantly higher than that in the HES40 group at H1, H3 and $10 \mathrm{~min}(P<0.05$ or $P<0.01)$. Then, the DBP level in the HES200 group was significantly higher than those in the other groups at $\mathrm{H} 2(P<0.05$ or $P<0.01)$, and it was also significantly higher than that in the HES40 group at H3, 10 min and 20 min $(P<0.05$ or $P<0.01)$. The MAP level in the HES200 group was significantly higher than that in the HES40 group $(P<0.01)$ at $\mathrm{H} 1$ and $\mathrm{H} 2$, and it was also significantly higher than that in the Gel group at $\mathrm{H} 2, \mathrm{H} 3$ and $60 \mathrm{~min}(P<0.05$ or $P<0.01$, Table 1$)$.

As displayed in Table 1, the PP level increased significantly at H3 compared with BL in the Gel, HES200 and HES130 groups $(P<0.05$ or $P<0.01)$, and it increased significantly at $60 \mathrm{~min}$ compared with $\mathrm{H} 3$ in the Gel and HES40 groups $(P<0.05)$. The HR level significantly increased at $60 \mathrm{~min}(P<0.01)$ compared with $\mathrm{BL}$ and $\mathrm{H} 3$ 


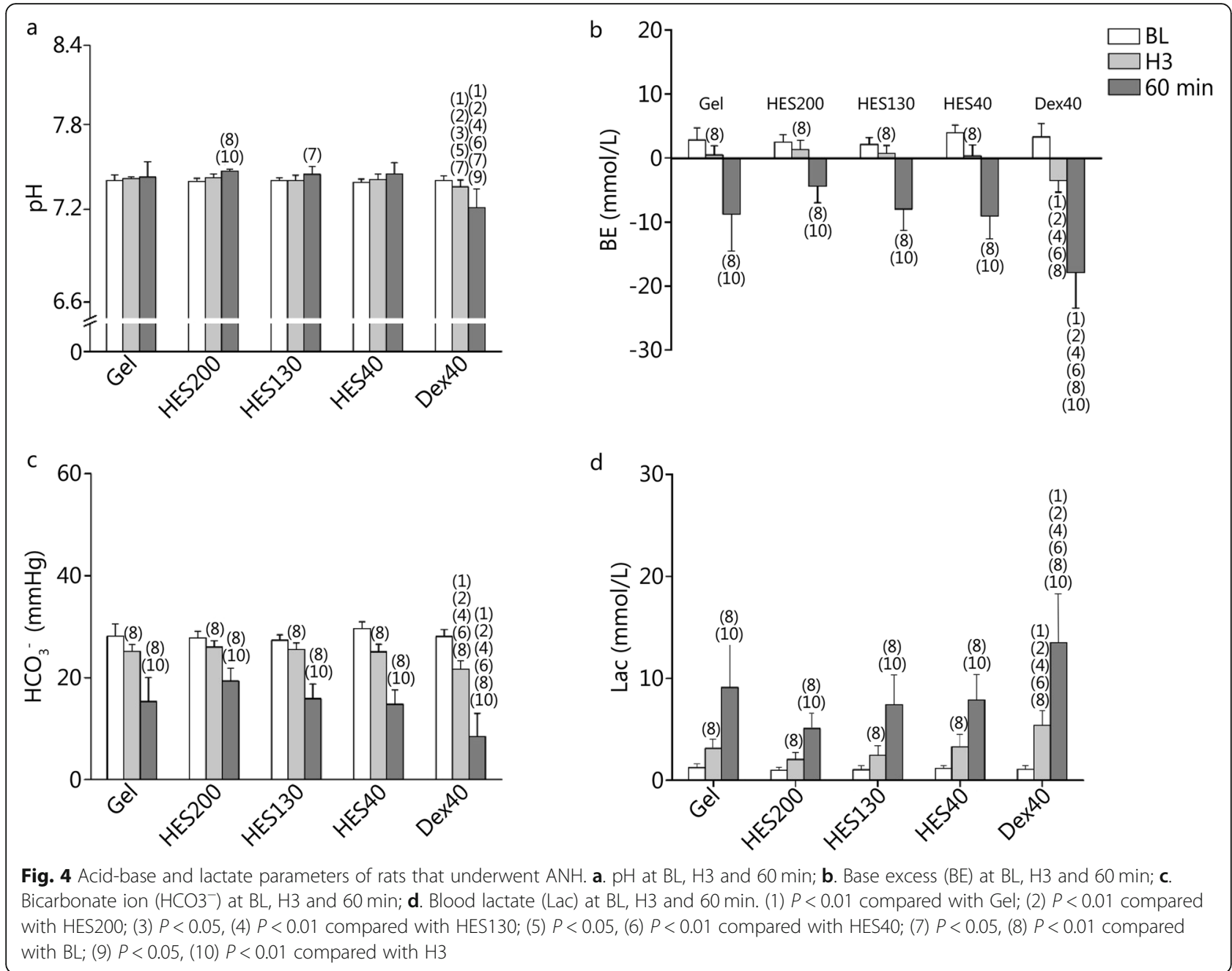

in the Gel, HES130 and HES40 groups. Furthermore, in the Dex40 group, the HR level increased significantly at $\mathrm{H} 3$ and $60 \mathrm{~min}$ compared with $\mathrm{BL}(P<0.01)$ and was significantly higher than those in the Gel and HES200 groups at $\mathrm{H} 3(P<0.05$, Table 1$)$.

The PP level in the Dex40 group was lower than those in the other groups at $\mathrm{H} 1(P<0.01)$. At $10 \mathrm{~min}$, it was higher than that in the HES40 group $(P<0.05)$. At $60 \mathrm{~min}$, it was lower than that in the HES200 group $(P<0.05)$. The HR level in the Dex40 group began to increase significantly from $\mathrm{H} 2$. At $\mathrm{H} 2$, it was higher than that in the Gel group $(P<0.05)$. At $\mathrm{H} 3$, it was higher than those in the Gel and HES40 groups $(P<0.05)$. At 10 min, it was higher than those in the other groups $(P<0.05$ or $P<0.01)$. At $20 \mathrm{~min}$, it was higher than those in the Gel, HES200 and HES130 groups $(P<0.05$ or $P<0.01)$. At $30 \mathrm{~min}$, it was higher than those in the HES200 and HES130 groups $(P<0.01$, Table 1$)$.

The correlation between $\triangle \mathrm{MAP}$ and $\triangle \mathrm{BE}$ is demonstrated in Fig. 6a, and the $R^{2}$ was 0.36 , which was statistically significant $(P<0.05)$. Furthermore, the correlation between $\triangle \mathrm{MAP}$ and $\triangle \mathrm{Lac}$ was analyzed and is demonstrated in Fig. 6b. The $R^{2}$ was 0.39 , which was statistically significant $(P<0.05)$.

\section{Discussion}

Physicochemical properties of the plasma expanders

In the present study, Gel had a lower intrinsic viscosity than HES200, HES130 and Dex40, but in a mixture with red cells and plasma, Gel had a higher viscosity at low shear rates compared with plasma, HES200 and HES130. Gel also resulted a higher viscosity than plasma at all shear rates. These data are similar to the result of a previous study reporting that Gel increased the blood viscosity [25]. Since viscosity at low shear rates indicates the aggregation of red cells, the results in this study are consistent with the finding that Gel induces red cell aggregation [26].

The $R_{h}$ increased with the increase of the molecular weight. The principle of colloid administration is that solutions containing macromolecules may act as better intravascular volume expanders compared with crystalloid 


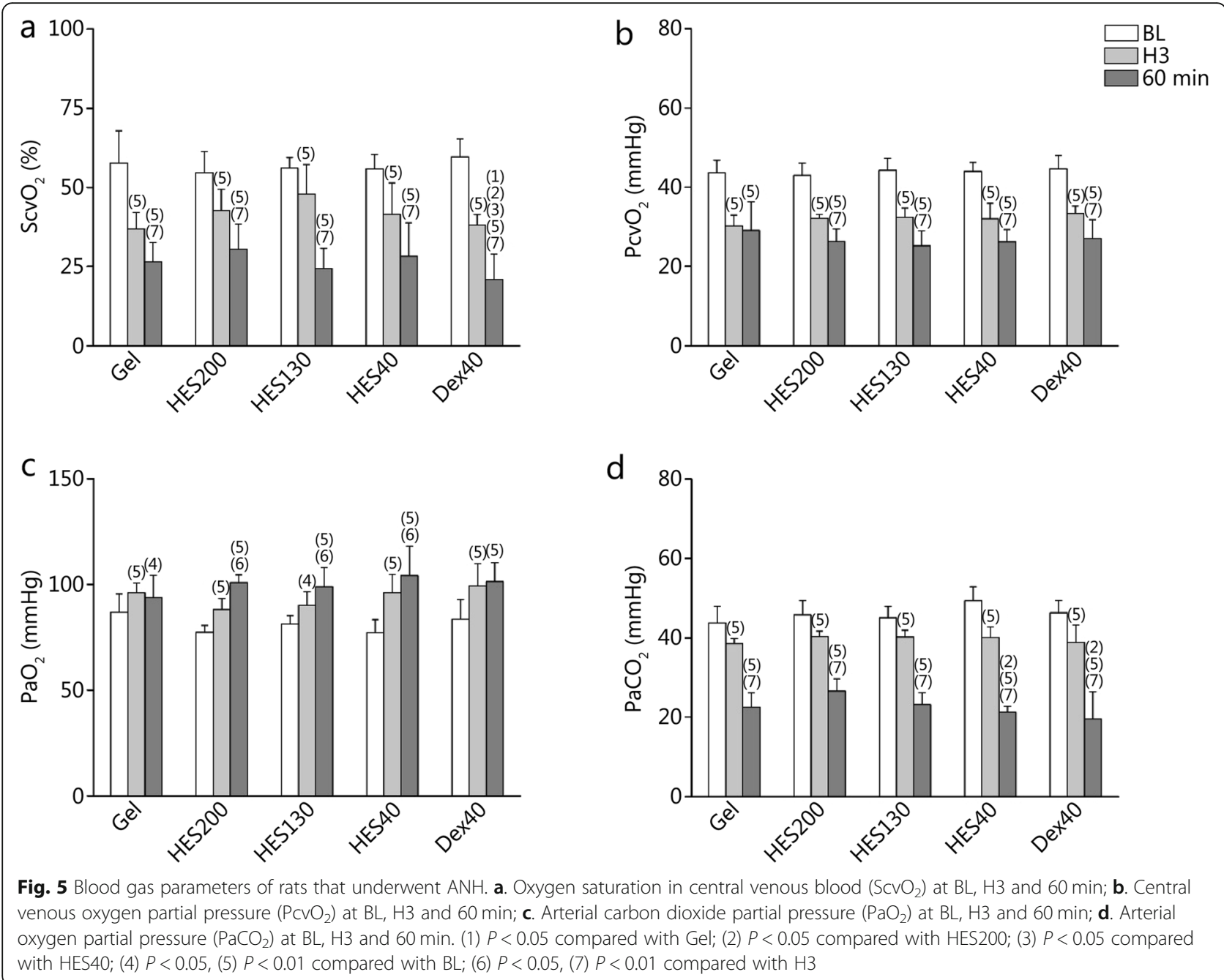

fluids and will increase the plasma COP [9]. For the intrinsic injection concentration, Dex40 had the highest COP, followed by HES40, Gel, HES130, and HES200. This is because the intrinsic concentration of Gel is $4 \%$, while that of the other plasma expanders is $6 \%$. When all colloids were diluted to a concentration of $2 \%$, the COP of Gel was significantly higher than that of Dex40. For all colloids, $\mathrm{R}_{\mathrm{h}}$ and COP show poor correlation, while for HES40, HES130 and HES200, $\mathrm{R}_{\mathrm{h}}$ and COP show good correlation. Therefore, at a certain concentration, the COP of hydroxyethyl starch decreases with the increase of the molecular weight.

\section{The rodent model of severe $\mathrm{ANH}$}

The Hct was reduced by approximately $20 \%$ in each step (Fig. 1) and was expected to reach $40 \%$ of the baseline level at the end of hemodilution. In accordance with accepted standards, the degree of normovolemic hemodilution was classified as mild (Hct $>30 \%$ ), moderate (Hct 20-30\%), or severe (Hct 10-20\%) [27]. The present rodent model of $\mathrm{ANH}$ reached Hct 16\%, indicating severe hemodilution.

At $60 \mathrm{~min}$ after $\mathrm{H} 3$, the Hct and $\mathrm{Hb}$ concentrations were significantly higher than they were at $\mathrm{H} 3$, which suggests that the volume expansion effect of the plasma expanders was weakening and that the total circulation volume was reduced because of the in vivo metabolism of the plasma expanders. For example, Dextran can be metabolized into $\mathrm{CO}_{2}$ and $\mathrm{H}_{2} \mathrm{O}$ by dextranase at a rate of $70 \mathrm{mg} / \mathrm{kg}$ bodyweight every $24 \mathrm{~h}[28,29]$. The half-life of Dextran $(28,000$ to $36,000 \mathrm{Da})$ as determined by its molecular weight in the human body is approximately $30 \mathrm{~min}[28]$.

In the preparation of the present rodent model, the speed of infusion or hemorrhage was $20 \mathrm{ml} / \mathrm{h}$, which reduced the Hct to 80,60 , and $40 \%$ of the baseline value in the three steps performed to attain ANH (Hct $=16 \%)$. Table 2 compares the present rodent model of $\mathrm{ANH}$ with the rodent model of HS (hemorrhaging approximately $40 \%$ of the total blood volume) which was 


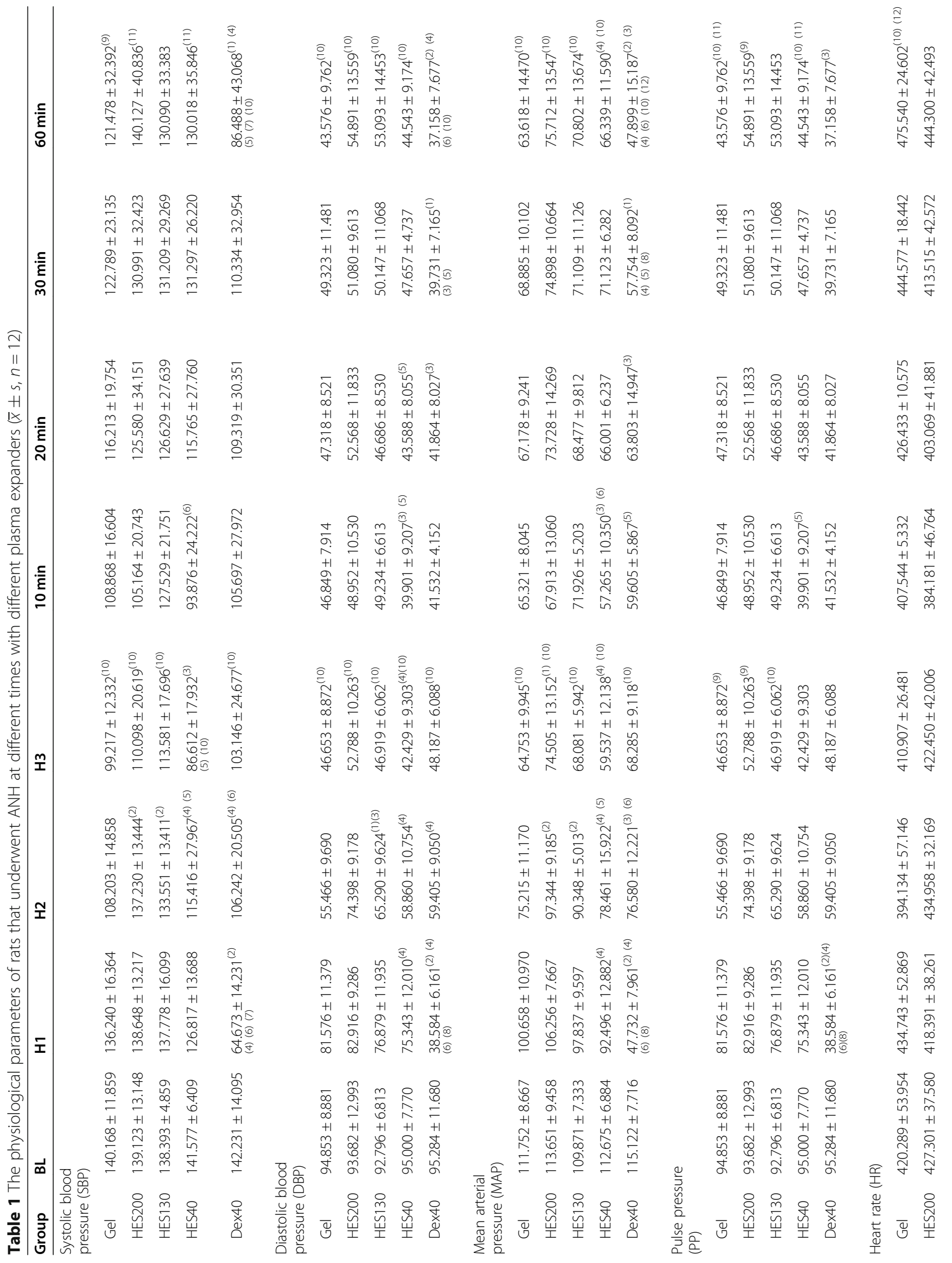




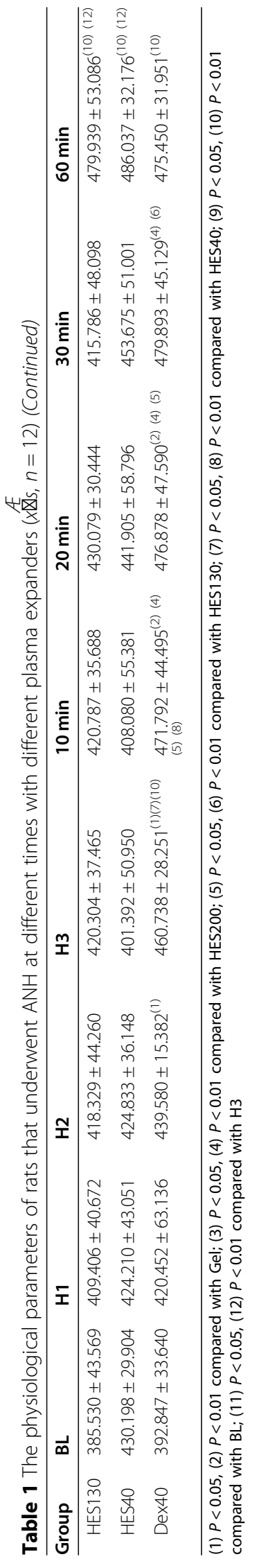



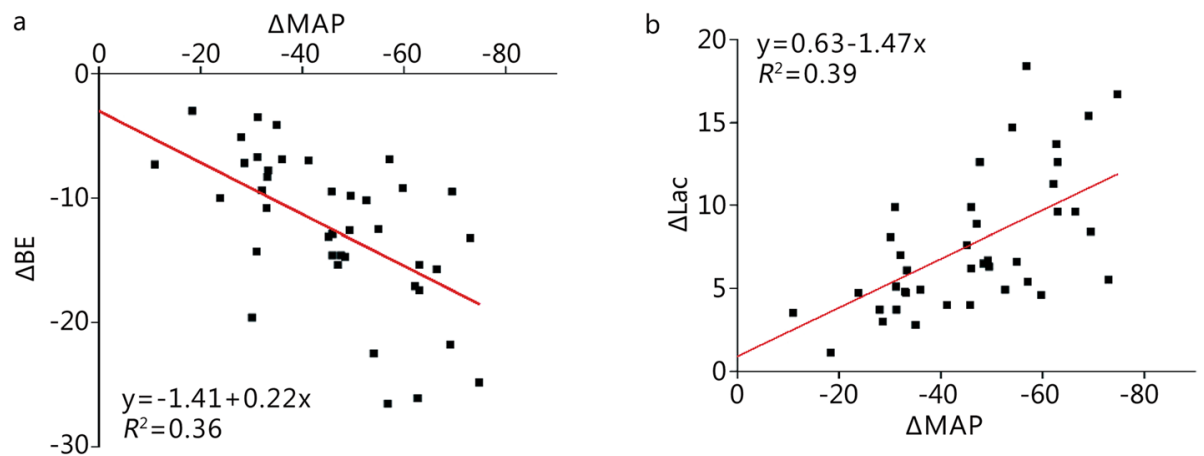

Fig. 6 Correlations between physiological parameters and blood gas parameters. a. The correlation between $\triangle \mathrm{MAP}$ and $\triangle \mathrm{BE}(P<0.05)$; b. The correlation between $\triangle \mathrm{MAP}$ and $\triangle \operatorname{Lac}(P<0.05)$

published in research by our lab [20, 30-32]. In both models, the $\mathrm{Hct}, \mathrm{Hb}, \mathrm{BE}, \mathrm{ScrO}_{2}$, and MAP decreased, and the Lac increased. However, the Hct and $\mathrm{Hb}$ decreased more in the ANH model than in the HS model. In addition, compared with the $\mathrm{HS}$ model, the $\mathrm{ANH}$ model resulted in smaller decreases in $\mathrm{BE}, \mathrm{ScvO}_{2}$, and MAP and a smaller increase in Lac, indicating more severe acidosis in the rodent model of HS [30, 32, 33].

In the process of model preparation, the SBP levels decreased gradually in all groups and increased back to the level of the baseline except for Dex40, and the DBP and MAP levels in all groups were reduced gradually, which corresponds with previous reporting that human and animal MAP was decreased during the process of ANH [34]. The DBP and MAP levels in all groups were lower than those of the baseline at all time points.

The reason may be that during the hemodilution, although the blood volume did not change significantly, the blood viscosity decreased, so the shear force on the blood vessels decreased, and the tension of the vascular smooth muscle changed, resulting in a decrease in the SBP. In addition, because of the decrease in the blood viscosity, the vascular peripheral resistance decreased, and the diastolic blood flow velocity increased, so the amount of blood retained in the aorta decreased, after

Table 2 The differences of variables between the rodent model of ANH and HS

\begin{tabular}{lll}
\hline Variables & Severe ANH in this study & HS \\
\hline $\mathrm{Hct}(\%)$ & $40 \%$ of $\mathrm{BL}$ & $83 \%$ of $\mathrm{BL} \mathrm{[32]}$ \\
$\mathrm{Hb}(\mathrm{g} / \mathrm{dl})$ & $4.34 \pm 0.13$ & $10.70 \pm 1.30[20]$ \\
$\mathrm{BE}(\mathrm{mmol} / \mathrm{L})$ & $-0.24 \pm 2.23$ & $-13.30 \pm 2.70[30]$ \\
$\mathrm{MAP}(\mathrm{mmHg})$ & $66.86 \pm 10.89$ & $38.00-40.00[30]$ \\
$\mathrm{Lac}(\mathrm{mmol} / \mathrm{L})$ & $3.60 \pm 1.32$ & $8.60 \pm 1.80[30]$ \\
$\mathrm{ScvO}_{2}(\%)$ & $40.13 \pm 6.10$ & $35.90 \pm 5.60[20]$
\end{tabular}

ANH Acute normovolemic hemodilution, $H S$ Hemorrhagic shock, HCt Hematocrit, BL Baseline, $H b$ Hemoglobin, BE Base excess, MAP Mean arterial pressure, $\mathrm{Lac}$ Blood lactate, $\mathrm{ScvO}_{2}$ The oxygen saturation in central venous blood which the DBP declined. Moreover, the changes in the MAP, which is approximately equal to the DBP plus $1 / 3$ of the PP, were consistent with the changes in the DBP. The insufficient oxygenation resulted in increased cardiac output due to compensatory mechanisms, so there was an increase in the blood volume ejected into the aorta and the lateral pressure on the arterial wall, which led to an increase in the SBP. In addition, a previous study [35] reported that the HR of patients undergoing ANH was basically unchanged, which was similar to the present findings. However, the HR in the Dex40 group was significantly increased, but the reason for this effect needs further research.

\section{Influence of different plasma expanders on acid-base, lactate and blood gas parameters}

In the present study, the $\mathrm{BE}$ was significantly lower in the Dex40 group than in the other groups at $\mathrm{H} 3$ and 60 $\mathrm{min}$. The $\mathrm{BE}$, which reportedly reflects the degree of body damage, is markedly decreased in HS [36], demonstrating that the fluctuation of the BE should be closely monitored and can be used to assess the degree of body damage in severe ANH.

At $60 \mathrm{~min}$, the Lac was significantly higher in the Dex40 group than in the other groups. Arterial Lac is a specific product of anaerobic metabolism and could reflect the tissue aerobic metabolism, which is an index of tissue hypoxia [37]. Hyperglycemia reportedly occurs during the early phase of HS [38]. Furthermore, due to the decrease in tissue oxygenation, there is a shift toward anaerobic glycolysis and an increase in Lac [39]. The elimination half-lives of Dex40, HES200, and Gel are $9.6 \pm 2.3 \mathrm{~h}, 12.1 \mathrm{~h}$, and $16.2 \mathrm{~h}$, respectively [28, 40], indicating that Dex40 is metabolized faster than HES200 and Gel. Moreover, at $60 \mathrm{~min}$, the $\mathrm{ScvO}_{2}$ was significantly lower in the Dex40 group than in the other groups, which might have been because Dex40 was metabolized rapidly in vivo, resulting in the reduction of its expansion effect, tissue perfusion, and the initiation of 
tissue hypoxia. $\mathrm{ScrO}_{2}$ is an important indicator of the patient's oxygen delivery, consumption, and cardiac output [41], which are closely connected to tissue hypoxia.

\section{Influences of different plasma expanders on physiological parameters}

The SBP was significantly lower in the Dex40 group than in the other groups at $60 \mathrm{~min}$. The reason for this might be that as the observation period was extended, the Dex40 was rapidly metabolized and excreted in vivo [28]. The concentration of Dex40 in the blood was further decreased because of the hemodilution and metabolism, which reduced the expansion effect of Dex40 and led to a decrease in the blood volume. Thus, the SBP was lower in the Dex40 group than in the other groups and did not return to the baseline level. In addition, the DBP and MAP of the HES200 group were maintained at higher levels compared with the other plasma expanders at some time points.

The SBP, DBP and MAP of anesthetized rats at baseline in this study were approximately $140 \mathrm{mmHg}, 94$ $\mathrm{mmHg}$ and $113 \mathrm{mmHg}$, respectively. These values are similar to rodent data from the study by Wang et at [31]. At H1, nearly $20 \mathrm{~min}$ after the beginning of hemodilution, the SBP, DBP and MAP of rats in the Dex40 group decreased to approximately $65 \mathrm{mmHg}, 39 \mathrm{mmHg}$ and $47 \mathrm{mmHg}$, respectively, while those of rats in other groups were approximately $136 \mathrm{mmHg}, 79 \mathrm{mmHg}$ and $100 \mathrm{mmHg}$, respectively. At $\mathrm{H} 2$, the SBP, DBP and MAP of rats in the Dex40 group returned to approximately $106 \mathrm{mmHg}, 59 \mathrm{mmHg}$ and $77 \mathrm{mmHg}$, respectively, without significant differences compared with rats in the Gel and HES40 groups. At the same time, rats administered Dex40 didn't show dyspnea or other symptoms of anaphylactoid reactions [42]; thus, further ANH was continued.

Studies have found that dextran induced hypotension in rats $[43,44]$. In a rodent study by Perez-Trepichio et al. [45], intraperitoneal administration of Dex40 before hemodilution and slow infusion of Dex40 during hemodilution avoided peripheral edema and early hypotension. In clinic, dextran-induced anaphylactoid reactions (DIAR) include mild anaphylactoid antibodyindependent reactions, and severe anaphylactic reactions [46], with incidences of $1: 718$ and $1: 821$, respectively [42]. It seems that in this study, rats administered Dex40 showed mild anaphylactoid antibody-independent reactions, which were approximately of the clinical severity of I or II [42].

Since blood gas measurements are invasive and hard to get in real time, correlation regression analysis between physiological parameters and blood gas parameters was conducted to determine whether physiological parameters can represent changes in blood gas parameters. Regression analysis was conducted on the data of the SBP, DBP, PP, MAP, BE, $\mathrm{ScvO}_{2}$ and $\mathrm{Lac}$ at $\mathrm{BL}, \mathrm{H} 3$ and $60 \mathrm{~min}$, as well as the difference value $(\Delta)$ between $60 \mathrm{~min}$ and $\mathrm{BL}$, in which SBP, DBP, PP and MAP were independent variables, with $\mathrm{BE}, \mathrm{ScvO}_{2}$ and $\mathrm{Lac}$ as dependent variables. Among them, compared with the baseline, changes of the MAP and changes of the $\mathrm{BE}$ had coefficients of determination $\left(R^{2}\right)$ of 0.36 and that of MAP and Lac was 0.39, which were the highest two values. Additional studies are needed to find noninvasive measurement methods and build more precise mathematical models since the correlations between physiological parameters and blood gas parameters in the present study are weak.

\section{Study limitation}

The rats in the present study are different from human subjects, so further studies are needed to extend the observation time and clarify the effects of dextran on a normovolemic hemodilution rodent model.

\section{Conclusions}

In the present study, the viscosity, $R_{h}$ and COP of plasma expanders were determined. Gel had a low intrinsic viscosity but may increase the whole-blood viscosity at low shear rates. For hydroxyethyl starch plasma expanders, the $\mathrm{COP}$ at a certain concentration decreases with the increase of the $R_{h}$. Namely, the $R_{h}$ and COP showed strong correlation among hydroxyethyl starch plasma expanders. The Hct was reduced to $40 \%$ of the baseline level, indicating that the rodent model of severe ANH was built. This change was accompanied by disturbances in the acid-base balance, lactate and blood gas. Dex40 showed a worse outcome in maintaining the acid-base balance and systemic oxygenation than the other plasma expanders. During the process of ANH, Dex40 displayed a V-shaped recovery graph for blood pressure, and the potential mechanism needs further investigation. HES200 had the advantage in sustaining the DBP and MAP at H2 during the ANH. During a $1 \mathrm{~h}$-observation after ANH, Gel, HES200, HES130, HES40 maintained the MAP above $55 \mathrm{mmHg}$.

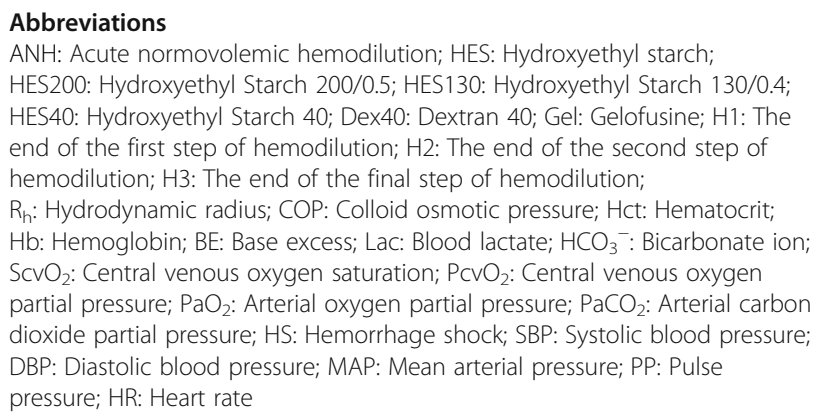

Acknowledgements

Not applicable. 


\section{Authors' contributions}

All authors conducted and contributed to the literature search. All authors contributed to the study design. GXY, ZW, and BTL collected the data. GXY and BTL interpreted the data. BTL and LZ wrote the article. All authors read and approved the final manuscript.

\section{Funding}

This work was supported by the National Key R\&D Program of China (2018YFC1106503)

\section{Availability of data and materials}

Not applicable.

\section{Ethics approval and consent to participate}

All animal experiments in this study were approved by the Laboratory Animal Center of the Academy of Military Medical Sciences.

\section{Consent for publication}

Not applicable.

\section{Competing interests}

The authors declare that there are no competing interests.

Received: 27 January 2020 Accepted: 18 October 2020 Published online: 11 November 2020

\section{References}

1. Tanner EJ, Filippova OT, Gardner GJ, Long Roche KC, Sonoda Y, Zivanovic O, et al. A prospective trial of acute normovolemic hemodilution in patients undergoing primary cytoreductive surgery for advanced ovarian cancer. Gynecol Oncol. 2018;151(3):433-7.

2. Fischer M, Matsuo K, Gonen M, Grant F, Dematteo RP, D'Angelica MI, et al. Relationship between intraoperative fluid administration and perioperative outcome after pancreaticoduodenectomy: results of a prospective randomized trial of acute normovolemic hemodilution compared with standard intraoperative management. Ann Surg. 2010; 252(6):952-8.

3. Grant MC, Resar LM, Frank SM. The efficacy and utility of acute normovolemic hemodilution. Anesth Analg. 2015;121(6):1412-4.

4. Jarnagin WR, Gonen M, Maithel SK, Fong Y, D'Angelica MI, Dematteo RP, et al. A prospective randomized trial of acute normovolemic hemodilution compared to standard intraoperative management in patients undergoing major hepatic resection. Ann Surg. 2008:248(3):360-9.

5. Crescini WM, Muralidaran A, Shen I, LeBlan A, You J, Giacomuzzi C, et al. The use of acute normovolemic hemodilution in paediatric cardiac surgery. Acta Anaesthesiol Scand. 2018;62(6):756-64.

6. Barile L, Fominskiy E, Di Tomasso N, Alpizar Castro LE, Landoni G, De Luca $M$, et al. Acute normovolemic hemodilution reduces allogeneic red blood cell transfusion in cardiac surgery: a systematic review and meta-analysis of randomized trials. Anesth Analg. 2017;124(3):743-52.

7. Kim TY, Kim DW, Jeong MA, Jun JH, Min SJ, Shin SJ, et al. Effects of acute normovolemic hemodilution on healing of gastric anastomosis in rats. Ann Surg Treat Res. 2018;95(6):312-8.

8. Kafi G, Akbarpour S, Arefi M, Behnoush B, Ahmadi Pishkuhi M, Barzegari N. Effect of hydroxyethyl starch on acidosis in patients with aluminum phosphide poisoning. Caspian J Intern Med. 2019;10(3):271-5.

9. Cartotto R, Greenhalgh D. Colloids in acute burn resuscitation. Crit Care Clin 2016:32(4):507-23.

10. Moerman A, Van Eeckhout C, Vanderstraeten $K$, De Somer F, Van Belleghem Y, De Hert S. The effect of hydroxyethyl starch 6\% 130/0.4 compared with gelatin on microvascular reactivity. Anaesthesia. 2016;71(7):798-805.

11. Demling RH, Kramer GC, Gunther R, Nerlich M. Effect of nonprotein colloid on postburn edema formation in soft tissues and lung. Surgery. 1984;95(5): 593-602.

12. Ghijselings I, Himpe D, Rex S. Safety of gelatin solutions for the priming of cardiopulmonary bypass in cardiac surgery: a systematic review and metaanalysis. Perfusion. 2017;32(5):350-62.

13. Myburgh JA, Finfer S, Bellomo R, Billot L, Cass A, Gattas D, et al. Hydroxyethyl starch or saline for fluid resuscitation in intensive care. $\mathrm{N}$ Engl J Med. 2012;367(20):1901-11.
14. Epelde F. Hydroxyethyl starch 130/0.42 versus Ringer's acetate in severe sepsis. Rev Clin Esp. 2013;213(2):114

15. Dai J, Tu W, Yang Z, Lin R. Case report: intraoperative management of extreme hemodilution in a patient with a severed axillary artery. Anesth Analg. 2010;111(5):1204-6.

16. European Medicines Agency: Hydroxyethyl starch solutions: CMDh introduces new measures to protect patients. https://www.ema.europa.eu/ en/news/hydroxyethyl-starch-solutions-cmdh-introduces-new-measuresprotect-patients. Accessed 29 June 2018.

17. Musia W, Michálek J. The influence of low process temperature on the hydrodynamic radius of polyNIPAM-Co-PEG thermosensitive nanoparticles presumed as drug carriers for bioactive proteins. Acta Pol Pharm. 2015:72(1):161-9.

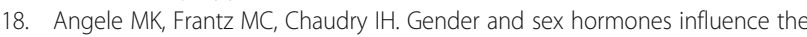
response to trauma and sepsis: potential therapeutic approaches. Clinics (Sao Paulo). 2006;61(5):479-88.

19. Albertsmeier M, Pratschke S, Chaudry I, Angele MK. Gender-specific effects on immune response and cardiac function after trauma hemorrhage and sepsis. Viszeralmedizin. 2014;30(2):91-6

20. Luo X, Chen G, You G, Wang B, Lu M, Zhao J, et al. Gradually increased oxygen administration promoted survival after hemorrhagic shock. Exp Biol Med (Maywood). 2016;241(14):1603-10.

21. Zhao J, You G, Yin Y, Zhang Y, Wang Y, Chen G, et al. Acute high-altitude exposure shortens survival after uncontrolled hemorrhagic shock in rats. J Surg Res. 2018;226:150-6.

22. Cao Y, Wang M, Yuan Y, Li C, Bai Q, Li M. Arterial blood gas and acid-base balance in patients with pregnancy-induced hypertension syndrome. Exp Biol Med. 2019;17(1):349-53.

23. O'Connor TA, Hall RT. Mixed venous oxygenation in critically ill neonates. Crit Care Med. 1994;22(2):343-6.

24. Nobahar MR, Chegini A, Behnaz F. Preoperative blood donation versus acute normovolemic hemodilution in cardiac surgery. Saudi J Anaesth. 2014;8(3):342-4

25. Chen G, Zhao J, Li P, Kan X, You G, Wang Y, et al. Effects of synthetic colloid and crystalloid solutions on hemorheology in vitro and in hemorrhagic shock. Eur J Med Res. 2015;20:13.

26. Scholz PM, Engeset J, Matheson NA, Gruber UF. Red cell aggregation induced by a high molecular weight gelatin plasma substitute. Eur Surg Res. 1971;3(6):428-35.

27. Messmer K. Hemodilution. Surg Clin North Am. 1975;55(3):659-78.

28. Klotz U, Kroemer H. Clinical pharmacokinetic considerations in the use of plasma expanders. Clin Pharmacokinet. 1987;12(2):123-35.

29. Gray I. Metabolism of plasma expanders studied with carbon-14-labeled dextran. Am J Phys. 1953;174(3):462.

30. Luo X, Yin Y, You G, Chen G, Wang Y, Zhao J, et al. Gradually increased oxygen administration improved oxygenation and mitigated oxidative stress after resuscitation from severe hemorrhagic shock. Anesthesiology. 2015; 123(5):1122-32.

31. Wang Y, Feng J, You G, Kan X, Qiu L, Chen G, et al. Heating pad for the bleeding: external warming during hemorrhage improves survival. J Trauma. 2011;71(6):1915-9.

32. Zhao L, Wang B, You G, Wang Z, Zhou H. Effects of different resuscitation fluids on the rheologic behavior of red blood cells, blood viscosity and plasma viscosity in experimental hemorrhagic shock. Resuscitation. 2009; 80(2):253-8

33. Chen G, You G, Wang Y, Lu M, Cheng W, Yang J, et al. Effects of synthetic colloids on oxidative stress and inflammatory response in hemorrhagic shock: comparison of hydroxyethyl starch 130/0.4, hydroxyethyl starch 200/0.5, and succinylated gelatin. Crit Care. 2013; 17(4):R141.

34. Johannes T, Mik EG, Nohe B, Unertl KE, Ince C. Acute decrease in renal microvascular PO2 during acute normovolemic hemodilution. Am J Physiol Ren Physiol. 2007;292(2):F796-803.

35. Laks J, Pilon RN, Klovekorn WP, Anderson W, MacCallum JR, O'Connor NE. Acute hemodilution: its effect of hemodynamics and oxygen transport in anesthetized man. Ann Surg. 1974;180(1):103-9.

36. Cannon JW. Hemorrhagic shock. N Engl J Med. 2018;378(4):370-9.

37. Patki A, Shelgaonkar V. Effect of $6 \%$ hydroxyethyl starch-450 and low molecular weight dextran on blood sugar levels during surgery under subarachnoid block: a prospective randomised study. Indian J Anaesth. 2010;54(5):448-52 
38. Slovin PN, Huang CJ, Cade JR, Wood CE, Nasiroglu O, Privette M, et al. Sodium pyruvate is better than sodium chloride as a resuscitation solution in a rodent model of profound hemorrhagic shock. Resuscitation. 2001; 50(1):109-15.

39. Kline JA, Maiorano PC, Schroeder JD, Grattan RM, Vary TC, Watts JA. Activation of pyruvate dehydrogenase improves heart function and metabolism after hemorrhagic shock. J Mol Cell Cardiol. 1997;29(9):2465-74.

40. Jungheinrich C, Neff TA. Pharmacokinetics of hydroxyethyl starch. Clin Pharmacokinet. 2005;44(7):681-99.

41. Squara P. Central venous oxygenation: when physiology explains apparent discrepancies. Crit Care. 2014;18(6):579.

42. Ljungström KG. Pretreatment with dextran 1 makes dextran 40 therapy safer. J Vasc Surg. 2006:43(5):1070-2

43. Berstad J. The initial phase of the dextran-induced anaphylactoid reaction in the rat: a comparison of inhibitors of the blood pressure fall. Acta Pharmacol Toxicol (Copenh). 1982;51(2):141-6.

44. Hoem NO, Briseid G, Ekelund S, Salvesen S. Effects of intravenous radiographic contrast media on the blood pressure and on factors of the contact activation system in the rat. Acta Pharmacol Toxicol (Copenh). 1986; 59(3):189-94.

45. Perez-Trepichio AD, Salgado AV, Jones SC. Isovolumic hemodilution with dextran 40 in the rat: effect on the development of peripheral edema and various physiologic parameters. J Pharmacol Exp Ther. 1991;256(3):913-6.

46. Farina JA Jr, Piccinato CE, Campos AD, Rossi MA. Comparative study of isovolemic hemodilution with 3\% albumin, dextran-40, and prophylactic enoxaparin (LMWH) on thrombus formation at venous microanastomosis in rats. Microsurgery. 2006;26(6):456-64.

Ready to submit your research? Choose BMC and benefit from:

- fast, convenient online submission

- thorough peer review by experienced researchers in your field

- rapid publication on acceptance

- support for research data, including large and complex data types

- gold Open Access which fosters wider collaboration and increased citations

- maximum visibility for your research: over $100 \mathrm{M}$ website views per year

At $\mathrm{BMC}$, research is always in progress.

Learn more biomedcentral.com/submissions 